\title{
Análise dos Sistemas Integrados de Gestão da UFRN sob a perspectiva da Nova Gestão pública
}

\section{Analysis of UFRN's Integrated Management Systems from the perspective of the New Public Management}

\begin{abstract}
Amanda Farias Galvão Santos. Mestranda em Direito. Universidade Federal do Rio Grande do Norte (UFRN) - Brasil.
\end{abstract} amanda_fgs@yahoo.com.br.

\section{RESUMO}

O presente artigo objetiva investigar como a Universidade Federal do Rio Grande do Norte porta-se diante das modernas práticas de administração pública, as quais pregam a superação das disfunções burocráticas, aumento da eficiência operacional e qualidade na prestação de serviços. O estudo desenvolve-se a partir da revisão teórica relativa ao modelo nominado como Nova Gestão Pública (NGP) e levantamento de dados obtidos nos Portais da UFRN (ufrn.br), com enfoque nos Sistemas Integrados de Gestão. Como metodologia, empregou-se as técnicas de pesquisa bibliográfica e documental. Feita a análise comparativa entre teoria e prática, conclui-se que o desenvolvimento e implantação do SIG-UFRN incorpora valores da NGP na gestão institucional, na medida em que a ferramenta promove transparência, celeridade, eficiência e economia no uso de recursos.

Palavras-chave: Nova Gestão Pública. Ensino superior. SIG-UFRN.

\section{ABSTRACT}

The present article aims to analyze how the Federal University of Rio Grande do Norte behaves towards the modern public administration practices, which preach the overcoming of bureaucratic dysfunctions, in pursuit of efficiency and quality in public services. The study is developed from the theoretical review about New Public Management (NGP) and survey of data obtained from the UFRN Portals (ufrn.br), with focus on Integrated Management Systems. The methodology used was bibliographical and documentary research. After a comparative analysis between theory and practice, it was concluded that the development and implementation of the SIG-UFRN incorporates NGP values in institutional management, insofar as the tool promotes transparency, agility, efficiency and economy in the use of resources.

Keywords: New Public Management. Higher Education. SIG-UFRN. 


\section{INTRODUÇÃO}

O modelo da Nova Gestão Pública surge no esteio de um conjunto de estudos e experiências inovadoras volvido à transposição e adequação de boas práticas da administração privada para a pública. Alberga conceitos como competitividade, eficiência, economicidade, transparência, celeridade, controle de resultados e accountability.

No Brasil, essa onda reformista adquiriu relevo com o advento do Plano Diretor da Reforma do Aparelho do Estado, formulado pelo então Ministério da Administração e Reforma do Estado (MARE), sob o comando de Luiz Carlos Bresser-Pereira. O intuito desse projeto era reduzir a máquina estatal, fortalecer o núcleo estratégico, publicizar atividades não essenciais, aprimorar a prestação de serviços e consagrar a eficiência como princípio administrativo.

Com a inserção de novas premissas, ações e projetos foram iniciados com o escopo de elevar a qualidade dos resultados e satisfação dos cidadãos. Todavia, inexiste o costume de avaliar os impactos dessas medidas no processo de implantação do gerencialismo, de modo que muitas são encerradas ou deixam de ser aprimoradas por ausência de estudos de acompanhamento e revisão.

Sob esse mote, o escopo desta pesquisa consiste em identificar a presença de pressupostos e características da NGP nas ferramentas de gestão adotadas pela Universidade Federal do Rio Grande do Norte. Porém, com o fulcro de evitar generalizações e facilitar a associação entre teoria e prática, fez-se mister a restrição do objeto: análise de pacote de software integrado ERP (Enterprise Resource Planning) elaborado e utilizado dentro dos quadros da instituição.

Nesse esteio, inserido no contexto hodierno de desenvolvimento e popularização das Tecnologias da Informação e Comunicação (TICs) nos ambientes de ensino/aprendizagem para gerenciar dados e processos organizacionais, o presente estudo investiga a hipótese de que os Sistemas Integrados de Gestão SIG-UFRN albergam valores da Nova Gestão Pública.

\section{PROCEDIMENTOS METODOLÓGICOS}

A metodologia empregada no desenvolvimento deste estudo adequou-se aos meandros da pesquisa descritiva qualitativa produzida. No decorrer da preparação, construção e finalização do trabalho foram utilizadas as técnicas de pesquisa bibliográfica e análise documental.

No processo de elaboração, três etapas foram adotadas. Na primeira, realizou-se a pesquisa bibliográfica, com consulta de livros, periódicos, teses e dissertações, a fim de fundamentar o estudo e identificar as diretrizes da Nova Gestão Pública.

Na segunda, procedeu-se com a coleta de dados secundários nos portais da UFRN, com ênfase no "sigaa.ufrn.br", "sigrh.ufrn.br", "sipac.ufrn.br". Entre os meses de janeiro e abril de 2020, as operações presentes no sistema SIG foram catalogadas para subsidiar a descrição analítica.

Apresentados os aspectos conceituais e características da NGP, bem como o contexto organizacional assinalado, a terceira etapa transcorreu com a avaliação do sistema SIG-UFRN em consonância com as diretrizes encontradas na primeira etapa da investigação ou revisão teórica.

Nesse ínterim, para o tratamento dos dados coletados (leitura, seleção de informações e interpretação), adotou-se a técnica de análise de conteúdo preconizada pela professora Laurence Bardin (2010) e estruturada em três fases: pré-análise; exploração do material; identificação e exposição dos resultados.

Adequado o esquema ao presente estudo, restou delineado o seguinte caminho: leitura flutuante; descrição analítica (do SIG-UFRN); codificação por categorias; separação por fio condutor comum (aproximação ou afastamento dos fundamentos da NGP). Após, com base na soma dos elementos comuns, infere-se a confirmação ou negação da hipótese segunda a qual o SIG-UFRN atende parâmetros da NGP.

Nesse mote, a perspectiva associativa foi elegida como estratégia para ressignificar o conteúdo das informações obtidas. Para cada característica da Nova Gestão Pública passível de aplicação aos sistemas informatizados de gestão foi atribuído um código com indicador relativo a sua promoção/aumento ou não, 
entre eles: eficiência ( $\uparrow$ ou $\downarrow$ ); qualidade na prestação de serviços ( $\uparrow$ ou $\downarrow$ ); competitividade $(\uparrow$ ou $\downarrow$ ); transparência ( $\uparrow$ ou $\downarrow$ ). Por derradeiro, os dados foram selecionados e separados em obediência a esses critérios. Panorama delineado, as conclusões puderam ser inferidas.

\section{REVISÃO TEÓRICA}

Existe um liame entre a definição do papel do Estado e o modelo de gestão pública utilizado (Oliveira, 2019). Liberalismo clássico, intervencionismo e neoliberalismo, esta foi a linha seguida pela maioria dos países quanto ao primeiro aspecto, guardadas as diferenças de tempo e grau. Por sua vez, atinente ao aperfeiçoamento no uso da estrutura e recursos estatais, reconhece-se três tipologias: patrimonialista, burocrática e gerencial (Junquilho, 2010; Lourenço, 2016).

Associado ao conjunto de reformas na máquina pública inspirado no setor privado e estruturas do mercado, o movimento New Public Management (NPM) segue a esteira do desenvolvimento do Estado Regulador em substituição ao Estado de Providência Social. Consoante Geoffrey Shepherd e Sofia Valencia (1996, p. 108), também recebe outras denominações: "gerencialismo, novo gerencialismo, nova gerência pública ou gerência baseada no desempenho".

\subsection{O surgimento da Nova Gestão Pública}

A crise econômica mundial, influenciada pelas crises do petróleo de 1973 e 1979, impulsionou a derrocada do modelo de Estado intervencionista. A era de prosperidade pós Segunda Guerra Mundial havia acabado. O cenário econômico, social e político era outro: crise fiscal em virtude do aumento do déficit público; dificuldade de o Estado atender as crescentes demandas sociais; fortalecimento do setor privado com o aumento do poder das empresas multinacionais e consequente enfraquecimento da capacidade dos Estados ditarem políticas macroeconômicas.

Diante desses fatores, houve a necessidade de redefinir o papel do Estado nas dimensões econômica, social e administrativa. O intervencionismo estatal deu lugar ao Estado Regulador. Nesse novo modelo, o Estado deixa de monopolizar alguns setores, participando apenas de maneira indireta, fomentando a iniciativa privada a fornecer serviços e atuar nos setores que eram, antes, de incumbência do Estado, sem deixar, contudo, de regular e fiscalizar a atuação dessas empresas no mercado por intermédio de órgãos estatais.

Frente ao esgotamento do modelo burocrático de inspiração weberiana, foram introduzidos, em larga escala, padrões gerenciais na administração pública, com o escopo de agilizar e flexibilizar a engessada máquina pública. Não se trata de anular fatores positivos como racionalidade, combate ao nepotismo e controle, mas corrigir disfunções e flexibilizar a prestação do serviço em prol da qualidade e eficiência.

O sucesso e as estratégias no implemento dessas políticas variaram conforme as peculiaridades locais. Iniciado durante as décadas de 1970 e 1980 em países anglo-saxônicos como Estados Unidos, Reino Unido, Austrália e Nova Zelândia (Junquilho, 2010, p. 58), o modelo restou copiado por nações latino-americanas, como o Brasil, por volta da década de 1990.

Nos Estados Unidos, segundo Ferlie, Asburner e Fitzgerald (1999, p. 37), "a pressão pela reforma do setor público antecedeu a eleição de Reagan, com a Lei de Reforma do Serviço Público, de 1978, aprovada na administração Carter" (Partido Democrata). Inobstante, o implemento efetivo da NGP como padrão de atuação ocorre no governo Reagan (Partido Republicano).

Do mesmo modo, a adesão concreta na Inglaterra ocorreu durante a era Thatcher (Partido Conservador). Entre as iniciativas, destacavam-se as privatizações, a descentralização estatal com separação entre núcleo estratégico e atividades de execução, a redução no quadro de funcionários, a terceirização de serviços públicos, o incentivo à capacidade profissional dos recursos humanos e as avaliações de desempenho.

Diferente da Inglaterra, Ana Paula Paes de Paula (2005) disserta que, na Nova Zelândia, as primeiras medidas foram introduzidas por governo trabalhista. Entre elas: concessão de maior autonomia aos burocratas; privatização de atividades comerciais e contratualização de recursos humanos. Outrossim, a partir 
do State Sector Act (1988) e do Public Finance Act (1989), promoveu-se a accountability mediante a obrigação de planejamento detalhado e avaliação de desempenho (controle de resultado).

Na Austrália, o marco integrador da NGP foi o Public Service Reform Act de 1984, o qual pregava a reorganização do serviço público. Entretanto, ainda na fase da campanha eleitoral de 1982, a tendência reformista já estava manifestada no lema do Partido Trabalhista (vencedor no pleito): "dirigir o Estado como uma empresa" (Mesquita \& Ferreira, 1997, p. 41).

Embora estejam embebidas nas premissas do pensamento econômico neoclássico, avesso à expansão das políticas keynesianas, a Nova Gestão Pública e a doutrina neoliberal nem sempre estão diretamente associadas. As primeiras tentativas de implementar a NGP demonstram a superação da fronteira política. Tanto governos de partidos trabalhistas, quanto de partidos conservadores acederam ao novo paradigma, com a devida adaptação ao seu plano governamental.

Diante do conceito de bem-estar social (welfare state), as demandas e as expectativas da população cresciam em níveis exponenciais. O aumento do gasto público e inchaço do quadro de pessoal culminou em aumento de impostos e inflação. A situação tornou-se insustentável com uma ampla massa de insatisfeitos. Entre as alternativas para resolver esse imbróglio econômico, político e social, emergiu a necessidade de reestruturar o Estado e tornar eficiente o uso dos recursos.

\subsection{Conceito e características do modelo}

Um dos primeiros trabalhos acadêmicos a estabelecer uma base conceitual para a NGP foi o artigo " $A$ public management for all seasons?", escrito por Christopher Hood e publicado em 1991. Em seu texto, o autor indica sete componentes relativos ao modelo: 1) administração pública profissional, proativa e responsiva; 2) definição clara de metas e avaliação por indicadores de desempenho; 3) ênfase no controle de resultados; 4) descentralização do setor público; 5) introdução de competição; 6) incorporação de práticas gerenciais do setor privado; 7) estímulo à disciplina e parcimônia no uso de recursos (Hood, 1991).

Por sua vez, Donald Kettl (2000) enumera seis características que ressaltam a passagem de um paradigma burocrático para outro mais gerencial: 1) ênfase na produtividade (eficiência); 2) serviço orientado para o resultado (qualidade) e para o cidadão (participação social); 3) redução de gastos, transparência e accountability, 4) descentralização (delegar responsabilidades); 5) adoção de mecanismos de mercado para a melhoria do desempenho; 6) necessidade de participação dos gestores em todo o ciclo de políticas públicas (formulação - execução - avaliação).

Ao discorrer sobre os objetivos desse modelo alternativo de estruturação da gestão pública, MatiasPereira (2016) assinala os seguintes: 1) alcançar maior qualidade e eficiência na prestação de serviços aos cidadãos; 2) descentralizar e flexibilizar procedimentos; 3) elevar o nível de transparência das operações administrativas; 4) conferir competitividade; 5) orientar serviços para o cumprimento de metas; 6) favorecer o controle social; 7) promover accountability.

Em síntese, a Nova Gestão Pública vincula-se ao conjunto de reformas e novas práticas administrativas, com inspiração no setor privado, volvido para a melhoria da eficiência, qualidade e eficácia na prestação de serviços públicos (Lapuente \& Walle, 2020). Em termos de estrutura organizativa, transforma a composição da Administração Pública, altera valores e redefine papéis.

Se a burocracia volta-se para os meios/processos e realça o controle preventivo (a priori), a NGP orienta-se para os resultados (controle a posteriori) e às necessidades do cidadão. Como estratégias para alcançar seus objetivos, propõe: o planejamento estratégico, a redução de custos, a flexibilidade gerencial, a descentralização administrativa, a competição interna, o incentivo ao desenvolvimento de inovações e uso de tecnologias de informação e comunicação (TICs).

Algumas das grandes desvantagens do emprego da burocracia eram o formalismo excessivo, a papelada desnecessária e o apego cego às normas, o que terminava por afastar e oprimir o cidadão. As instituições ficavam estagnadas e não acompanhavam as mudanças do ambiente externo. Em consequência disso, o Estado distanciava-se do seu escopo maior, qual seja, a busca do bem comum. 
Diante disso, restou necessária a adoção de uma abordagem gerencial. Aposta-se, assim, na gestão de competências para os recursos humanos: identifica saberes, define responsabilidades, cria indicadores de desempenho, adota modelos de avaliação conforme a função exercida, além de investir na autonomia e capacitação para estimular a criatividade dos servidores, conferir dinamismo e garantir o atendimento das especificidades de uma sociedade plural.

Não obstante a introdução de novas diretrizes, verifica-se a permanência de alguns postulados da administração burocrática, a exemplo da meritocracia como principal via de admissão, da estruturação do quadro em carreiras, da avaliação de desempenho e da ênfase em treinamento do pessoal.

Atinente ao desenho institucional, a Nova Gestão Pública prega a redução da máquina pública sem a perda da eficiência, eficácia e efetividade na prestação dos serviços públicos. Para tanto, propugna-se a descentralização, a desregulamentação, a orientação para resultados, a adoção de regimes de incentivo à competitividade, a inclusão de atores e parceiros privados, maior responsividade e minimização dos custos (Guerrero, 2019).

Com a delimitação da ação estatal ao planejamento e funções estratégicas, pode-se transferir serviços não exclusivos para entidades privadas por contratos e parcerias, além de reservar-lhes a produção prioritária de bens e serviços. Como medidas auxiliares, cite-se: a privatização das empresas estatais; a terceirização das atividades de apoio e o downsizing.

Ademais, para a construção de uma administração pública mais eficiente e voltada para atender os anseios populares, a NGP pugna por uma maior participação social, tanto na formulação quanto na avaliação de políticas públicas, bem como maior transparência a fim de viabilizar o controle social.

No plano de aplicação dessas propostas, pode-se mencionar: participação direta da sociedade em conselhos de administração; criação de portais com a disponibilização dos dados governamentais para acesso e controle social; realização de audiências e consultas públicas; definição de canais de atendimento, como ouvidorias.

A conformação de uma administração mais responsiva ao cidadão aliada à priorização do controle a posteriori trouxe o conceito de accountability para a agenda das atividades estatais. Consoante Tomio e Robl Filho (2013, p. 30), o termo indica "a necessidade de uma pessoa ou instituição que recebeu uma atribuição ou delegação de poder prestar informações e justificações sobre suas ações e seus resultados, podendo ser sancionada política, pública, institucional e/ou juridicamente por suas atividades".

\subsection{O ingresso da NGP no Brasil}

A propagação das ideias reformistas entranhadas no movimento Nova Gestão Pública adentrou em terras brasileiras na década de 1990. Em que pese a inexistência de consumação de um Estado de Bem-Estar Social no país, havia um padrão de desenvolvimento econômico por intervenção estatal, bem como uma mescla de práticas burocráticas com patrimonialistas na gestão.

Impactado pelas crises econômicas mundiais, rigidez normativa, crise fiscal e inflação, no primeiro governo do ex-presidente Fernando Henrique Cardoso criou-se o Ministério da Administração e Reforma do Estado (MARE), pasta comandada por Luiz Carlos Bresser-Pereira e encarregada de delinear uma proposta de reorganização institucional fulcrada na redução de custos, promoção de eficiência e qualidade dos serviços prestados.

Fruto dos estudos realizados, emerge o Plano Diretor da Reforma do Aparelho do Estado (PDRAE) em 1995, o qual adotou o termo administração gerencial para o modelo pautado em metas de eficiência e qualidade que pretendia construir. Pregava o redimensionamento do Estado, a descentralização, a superação das disfunções burocráticas, a flexibilização da gestão e a integração dos cidadãos nos processos. Acerca da alteração referente ao novo foco do controle ser os resultados e não os meios, o projeto explicitava que a:

administração pública gerencial vê o cidadão como contribuinte de impostos e como cliente de seus serviços. Os resultados da ação do Estado são considerados bons não porque os processos administrativos estão sob controle e são seguros, como quer a administração 
pública burocrática, mas porque as necessidades do cidadão-cliente estão sendo atendidas (Brasil, 1995, p.17).

Como ponto de partida para reorganização da estrutura estatal, dividiu-a em quatro setores: núcleo estratégico; atividades exclusivas; serviços não exclusivos e produção de bens de serviços para o mercado. Para as duas últimas, indicava o repasse das atividades para o setor público não estatal (publicização) ou para o setor privado. Recomendava também a formalização de parcerias para atuação conjunta.

Nesse ponto, o PDRAE representou uma quebra na visão dicotômica público-privada tradicional, pois apoiava-se na atuação conjunta e articulada entre Estado e setores diversos da sociedade (Brasil, 1995). As organizações sociais e o terceiro setor são exemplos desses novos arranjos jurídico-institucionais e organizacionais propostos.

Entretanto, a implantação do Plano Diretor sofreu alguns revezes diante da resistência do Congresso Nacional, funcionalismo e parcela do povo. A iniciativa acerca da ampla criação de organizações sociais e agências autônomas (reguladoras e executivas) não alcançou a projeção esperada.

Não obstante, as matrizes propositivas perduraram e foram aprimoradas ao longo dos anos. Algumas, inclusive, por alterações legislativas. A título de exemplo, a eficiência foi erigida como princípio da administração pública no art. 37, caput, da Constituição Federal de 1988 pela Emenda Constitucional nº 19/1998. Por sua vez, noções de equilíbrio fiscal e accountability ganharam vigor com a Lei de Responsabilidade Fiscal (LC n 101/2000) complementada pela Lei de Transparência (LC n 131/2009).

\section{ANÁLISE DA INOVAÇÃO: OS SISTEMAS INTEGRADOS DE GESTÃO DA UNIVERSIDADE FEDERAL DO RIO GRANDE DO NORTE}

A Nova Gestão Pública trouxe à baila a necessidade de desenvolver ferramentas e ações inovadoras, notadamente para a promoção da eficácia, eficiência e controle de resultados. Nessa senda, os sistemas digitais encontram seu fundamento, unificam fontes de dados, agilizam processos, reduzem gastos e resíduos de produção.

Diante disso, o foco desse capítulo será a análise de uma iniciativa inovadora em gestão pública desenvolvida na Universidade Federal do Rio Grande do Norte, instituição de ensino criada pela Lei Estadual (RN) n 2307/1958 e federalizada pela Lei no 3848/1960. Trata-se dos Sistemas Integrados de Gestão SIG-UFRN.

\subsection{Descrição da inovação}

Os Sistemas Integrados de Gestão da Universidade Federal do Rio Grande do Norte (SIG-UFRN) constituem um conjunto de sistemas corporativos informatizados desenvolvidos e remodelados pela Superintendência de Informática (SINFO) nos últimos dezessete anos (2003-2020).

Trata-se de um Enterprise Resource Planning (ERP), software capaz de integrar todos os dados e processos de uma organização em sistema único. Além de evitar inconsistências e redundâncias, possui padrão flexível, pois a construção dos módulos dar-se-á em consonância com o tipo de negócio/serviço da empresa/instituição (Caiçara Jr, 2015).

No caso da UFRN, compõe-se por três sistemas principais, cada qual com uma função precípua: SIGAA (gestão de atividades acadêmicas); SIGRH (gestão de recursos humanos) e SIPAC (gestão de patrimônio, administração e contatos).

Em acréscimo, insta mencionar o SIGAdmin (Gestão da Administração e Comunicação), o qual possui acesso restrito e é responsável por gerenciar fatores comuns aos sistemas: "usuários, permissões, unidades, mensagens, notícias, gerência de sites e portais, dentre outras funcionalidades" (UFRN, 2020).

Existe um perfil padrão relacionado ao(s) vínculo(s) da pessoa com a instituição: estudante, servidor técnico, professor, gestor, secretário, pró-reitor. O vínculo determina para qual(is) sistema(s) haverá acesso. Por exemplo, mediante aposição da matrícula e senha, estudantes adentrarão no portal discente do SIGAA. 
Atinente às permissões, cada portal do sistema possui módulos específicos com funcionalidades direcionadas ao usuário. Desta feita, caso haja a necessidade de acrescer atribuição, será necessária a solicitação e concessão pelos administradores do sistema.

Concebidos como uma ferramenta para auxiliar na gestão dos processos, os sistemas SIG-UFRN armazenam e compartilham informações em uma base de dados comum, com acesso unificado (login e senha iguais) e um mesmo padrão de visualização. Ademais, restam sincronizados com sistemas governamentais externos, como o SIAFI (Sistema Integrado de Administração Financeira do Governo Federal), conforme apresentado na figura abaixo:

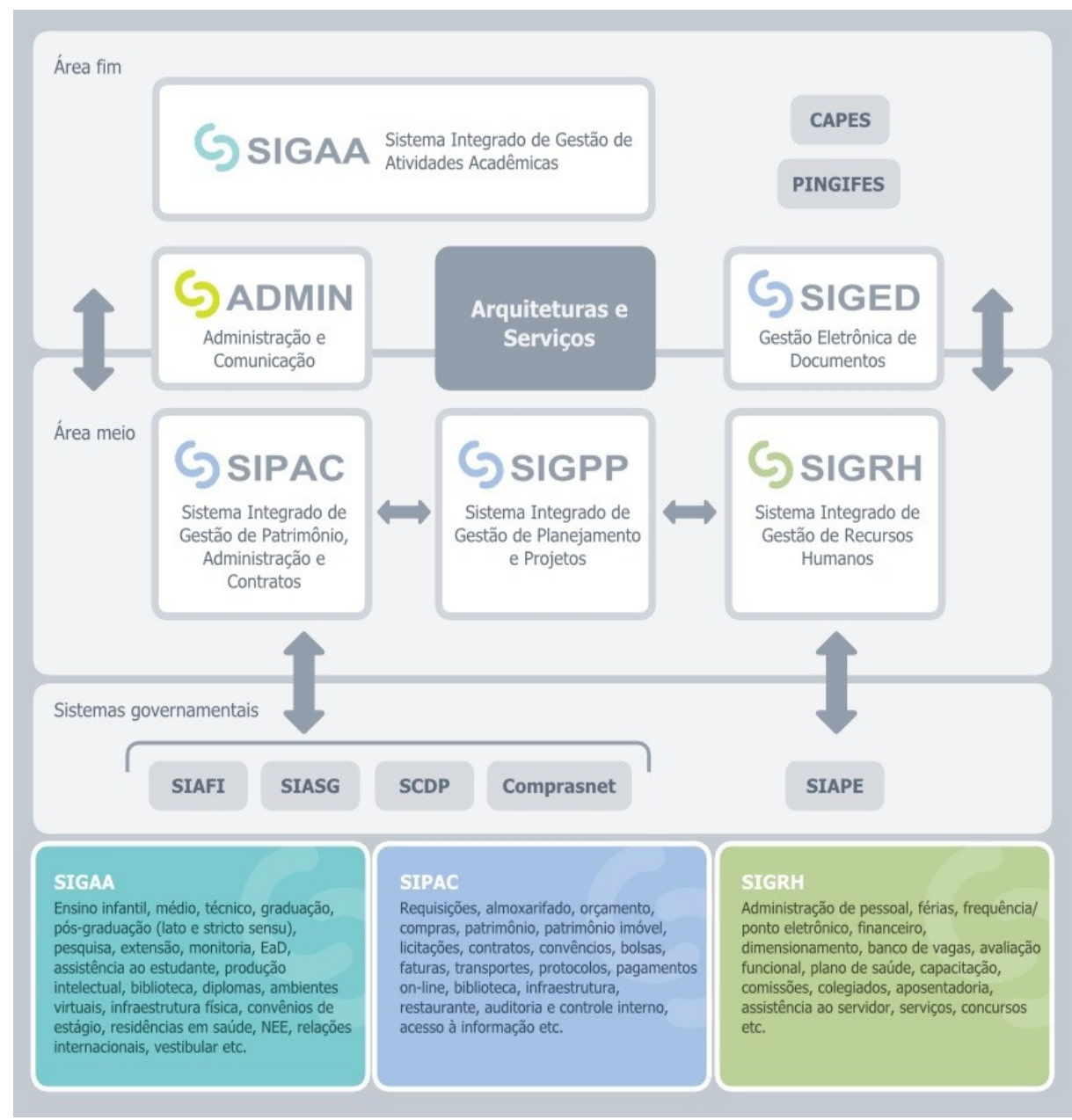

Figura 1 - Áreas do Sistema SIG-UFRN

Fonte: UFRN (2020c, p. s/n).

Procedimentos das atividades-meio e das atividades-fim foram abrangidos pelo SIG. A título de exemplo, férias, avaliação funcional, frequência e capacitação de servidores passaram a ser gerenciadas pelo SIGRH, sendo resguardada a interação com o Sistema Integrado de Administração de Recursos Humanos do Governo Federal (SIAPE) quando devido.

No SIPAC, operações relacionadas com protocolo e acompanhamento de processos, memorandos, contratos e patrimônio da instituição foram informatizados. Cada unidade administrativa visualiza o orçamento a ela distribuído, podendo planejar e acompanhar as despesas realizadas por gráficos e valores numéricos.

Noutra toada, o SIGAA orienta-se para a organização e execução das atividades-fim da instituição, ou seja, a área acadêmica. Possui módulos de graduação, pós-graduação, formação complementar, ensino técnico, médio e infantil. $\mathrm{Na}$ área pública, acessível a qualquer interessado, os principais documentos e 
informações sobre o funcionamento dos cursos ofertados, processos seletivos, acervo das bibliotecas, bem como acerca das ações de pesquisa e extensão estão disponíveis.

No Portal do Discente e do Docente, uma importante inovação foi a criação das Turmas Virtuais, ambientes digitais de aprendizagem, onde estão reunidas todas as informações de uma determinada turma, como participantes, plano da disciplina, fóruns, chats, frequência, notas, materiais e atividades. Aumentou, portanto, a interação entre alunos e professores no processo de ensino e apreensão do conhecimento.

Criado sob padrões de usabilidade e com design participativo, o SIG-UFRN apresenta uma linguagem simples e objetiva, possui interfaces gráficas interativas e possibilita a participação dos usuários, com o escopo de entender e atender suas necessidades, de sorte que o sistema permanece em constante evolução, com o desenvolvimento de novos módulos e funcionalidades.

Os docentes e discentes, antes de consolidar turmas e efetivar matrículas para o próximo semestre letivo respectivamente, devem preencher a Avaliação Institucional. O próprio sistema impõe a obediência a esse ciclo, posto que surge automaticamente como etapa antecedente. A comunidade externa pode contribuir com avaliações, denúncias e sugestões de aprimoramento de práticas institucionais pelo canal de ouvidoria integrado ao portal eletrônico "fala.br".

Ao assegurar o acesso à informação e participação de todos, o sistema propicia o controle social. Ademais, com a adesão à programas de avaliação continuada promove o autoconhecimento com identificação de progressos e falhas, bem como fornece subsídios para aprimorar a gestão administrativa e a qualidade acadêmica.

Em que pese a relevância da implementação do SIG para o gerenciamento dos processos acadêmicos e administrativos da Universidade Federal do Rio Grande do Norte ser inegável, existem alguns pontos a serem melhorados. Em algumas oportunidades, verificou-se a ausência de informações ou presença de dados antigos.

Com o fulcro de ilustrar esse problema, colaciona-se a seguir a página pública disponível no SIGAA para a apresentação das informações do Departamento de Ciências Sociais da instituição. Retirada no dia 26 de maio de 2020, a imagem demonstra que a última notícia postada se refere ao período de matrículas para o semestre 2016.1. Além disso, embora a universidade possua uma extensa dimensão territorial, observa-se a ausência de indicação do endereço físico completo (com inclusão de setor e sala). Tampouco existe a indicação do endereço eletrônico da unidade.

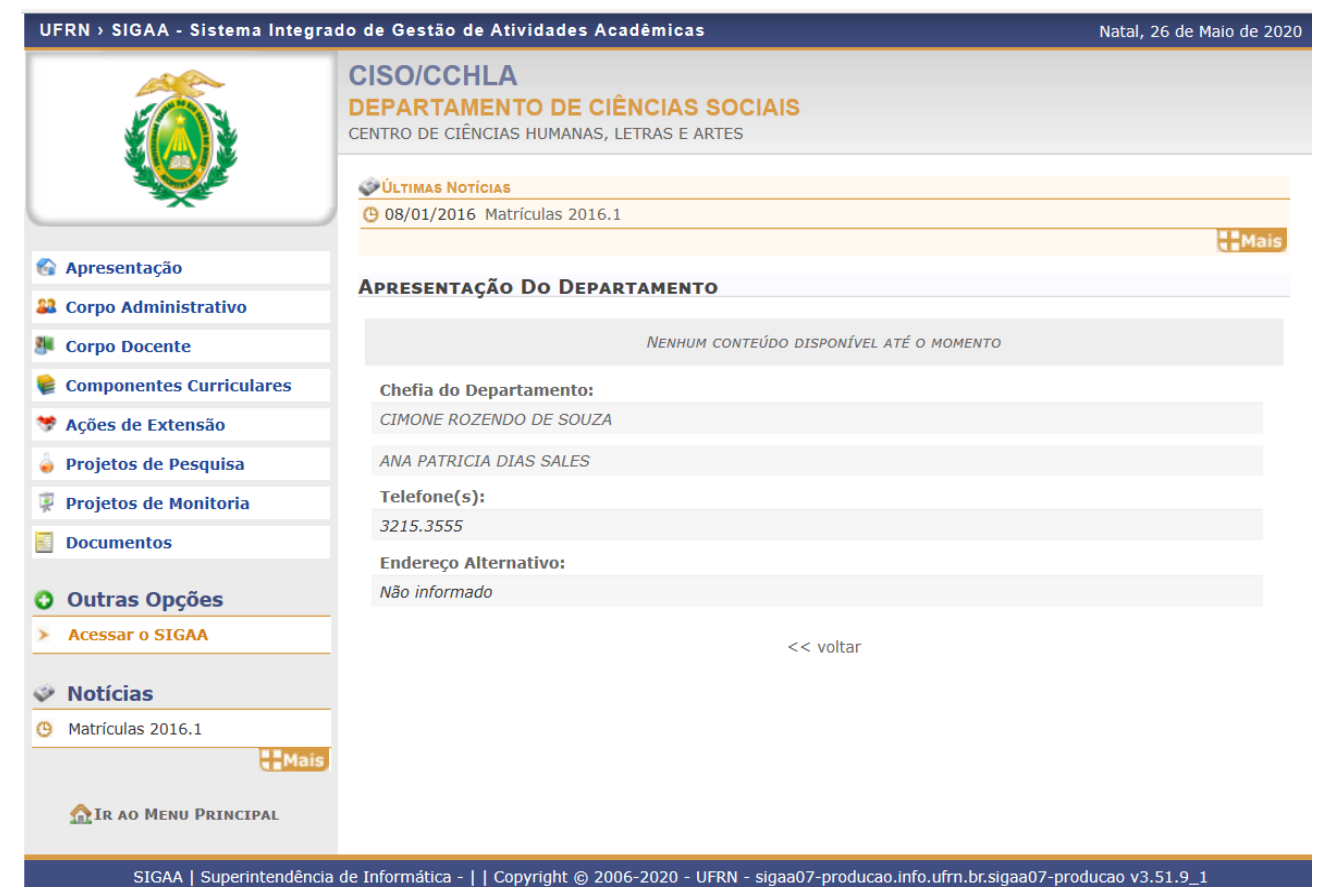

Figura 2 - Página do Departamento de Ciências Sociais no portal público do SIGAA-UFRN Fonte: UFRN (2020a, p. s/n). 


\subsection{Resultados: Análise comparativa entre teoria e ferramenta}

A mudança do modo de atuação do governo e de sua máquina administrativa em prol da superação dos entraves burocráticos e adoção da administração gerencial destaca o relevo do desenvolvimento e utilização de tecnologias da informação e comunicação como alternativas estratégicas relativas à governança, posto que aumentam a capacidade das organizações de prestarem seus serviços com qualidade, celeridade e lisura, atendendo as demandas sociais e incentivando o controle social, a transparência e práticas anticorrupção.

No âmbito das políticas de governo eletrônico, a gestão do conhecimento e informação pode ser compreendida como um conjunto de processos sistematizados capazes de assegurar a criação, coleta, organização e compartilhamento de conhecimentos produzidos por todos, diretores, servidores e cidadão, os quais podem auxiliar na tomada de decisões estratégicas (Brasil, 2004).

Sem dúvida, este é o panorama onde o sistema SIG-UFRN está inserido, visto que se constitui em uma importante ferramenta administrativa, volvida para a melhoria da qualidade dos serviços públicos prestados ao conferir agilidade na tramitação dos processos, redução de custos, aumento da segurança e confiabilidade dos dados dispostos.

Antes do sistema em comento, a maioria das operações eram manuais, o grau de informatização era reduzido, a papelada era abundante e havia dificuldade na obtenção da informação, visto que os dados não estavam armazenados em uma base comum e algumas vezes se perdiam entre pilhas de documentos (Ferreira, 2011).

As soluções eram precárias e setorizadas, em virtude da dificuldade de implantar um sistema de gestão do conhecimento uníssono. Decerto, a reunião e análise dos dados e informações geradas por toda a universidade era custosa e praticamente impossível, reduzindo a eficiência no serviço prestado para a comunidade acadêmica em algumas áreas e dificultando o planejamento estratégico.

Diante disso, tornou-se imperioso agregar valor às atividades institucionais mediante a exploração intensiva de $\mathrm{Tl}$, pois seu uso fornece "aos dirigentes públicos mais informações e de melhor qualidade, como apoio às suas decisões" e torna "a administração pública mais transparente, garantindo-lhe um caráter mais democrático e orientado para o cidadão" (Bresser-Pereira, 1998, p. 303).

Corroborando esse entendimento, em estudo sobre o implemento do Sistema Integrado de Gestão de Atividades Acadêmicas (SIGAA) em programas de Pós-Graduação da Universidade Federal do Pará, José Nilberlanio Vieira (2018, p. 33-34) acrescenta que:

as TIC podem colaborar para oportunizar serviços que antes eram prestados ao cidadão somente de forma presencial, por meio de canais digitais, como a internet, de maneira mais rápida e eficiente, objetivando permitir uma relação de maior proximidade entre o Estado e a sociedade, além de aumentar a qualidade do atendimento ao cidadão, reduzir a complexidade dos processos internos e ainda promover uma redução significativa de custos operacionais para o governo e também para o usuário.

Nessa esteira, porquanto o SIG seja uma plataforma em tempo real, os dados são gerados continuamente, permitindo a atualização e confiabilidade das informações. De fato, semestre a semestre, os coordenadores e diretores da universidade podem monitorar quantos alunos evadiram, reprovaram, trancaram disciplinas, entre outros aspectos.

Do mesmo modo, o controle orçamentário pode ser realizado com maior rigor pela análise dos balanços financeiros gerados paulatinamente pelo sistema após cômputo de compras ou outras despesas. $E$, pelo mesmo motivo, a base de dados sobre os recursos humanos permanece atualizada.

Outrossim, cumpre ressaltar que diante da implementação do projeto dos sistemas integrados de gestão, os procedimentos em papel foram paulatinamente substituídos pelos eletrônicos, reduzindo custos operacionais (material, tempo e esforço) e atendendo ao Decreto $n^{\circ}$ 8539/2015, o qual pugna pela migração de processos administrativos para o meio digital.

$\mathrm{O}$ aumento da conectividade permite uma intercomunicação e interoperabilidade dos diversos usuários com um menor consumo de tempo e recursos, otimizando os processos de trabalho inerentes à 
gestão acadêmica e atividades meio, dando concretude aos princípios da economicidade e eficiência aplicados na Administração Pública.

Diversas operações foram descentralizadas pelo sistema de gestão. A depender do perfil de acesso ao sistema, as permissões (padronizadas ou acrescentadas) conferem maior autonomia e o percurso necessário para o atendimento de uma solicitação pode ser reduzido. Diante disso, os recursos humanos e materiais restaram otimizados.

Quando se automatizam processos, o atendimento adapta-se às necessidades das pessoas, visto que oferece aos usuários maior facilidade e flexibilidade no uso, o que torna a experiência mais agradável, principalmente quando as ferramentas são simples e intuitivas. Com o acesso ao SIGAA, por exemplo, os alunos podem interagir nos fóruns e turmas virtuais, bem como obter histórico e outros documentos sem necessidade de carimbos e assinaturas físicas.

Além de atender às necessidades da comunidade acadêmica, o SIG-UFRN possui áreas públicas com informações e serviços úteis aos cidadãos em geral, inclusive com a possibilidade de entrar em contato com a ouvidoria. Demandas por informações podem ser cumpridas em tempo recorde em face da base integrada de dados (Gadelha, 2020).

Referida ferramenta caminha na esteira das modernas práticas de gestão pública, possibilitando maior fiscalização, controle e responsabilização das práticas dos gestores perante a sociedade. Por fortalecer o processo de elevação da transparência e aperfeiçoar a gestão fiscal, constitui mecanismo auxiliar para o cumprimento das exigências da Lei de Responsabilidade Fiscal.

Trata-se, portanto, de um mecanismo de accountability, a qual exige maior transparência das ações dos servidores e a garantia do direito de acesso à informação ao público, voltando-se para a eventual responsabilização, revisão de atos e desenvolvimento de práticas democráticas.

Ademais, assiste razão à Juan Moreira e Celio Lopes (2016) quando agregam as questões de responsabilidade social e desenvolvimento sustentável ao papel das Instituições de Ensino Superior (IES), revertendo tanto na difusão de conhecimento, quanto na adoção de práticas concretas, pois a entidade precisa assumir uma postura de referência perante a comunidade.

Como instituição pública federal, a universidade precisa adotar práticas administrativas abertas e transparentes capazes de atender o interesse público. Os portais com informações acessíveis a todos, além de mecanismo de gestão, cumprem a Lei no 12.527/2011 que, em seu art. 8, reza que "é dever dos órgãos e entidades públicas promover, independentemente de requerimentos, a divulgação em local de fácil acesso, no âmbito de suas competências, de informações de interesse coletivo ou geral por eles produzidas ou custodiadas".

Nesse diapasão, de acordo com notícia publicada em 8 de maio de 2020 por Gadelha (2020):

A Universidade Federal do Rio Grande do Norte (UFRN) é a primeira colocada entre as universidades brasileiras com mais conjuntos de dados no Portal Brasileiro de Dados Abertos, ferramenta do governo federal que disponibiliza informações públicas para acesso e utilização pelos cidadãos. Apenas a UFRN dispõe de 83 conjuntos, que reúnem informações sobre áreas diversas da instituição - servidores, alunos, ensino, pesquisa, extensão, entre outras.

Por derradeiro, insta consignar a relevância da adoção da tecnologia da informação em comento como instrumento de apoio à Administração Pública, ao possibilitar maior alcance na oferta de serviços e abrir espaço para o exercício da cidadania e controle social. No plano organizacional, a gestão da informação e conhecimento tornou-se mais efetiva, tendo em vista que facilitou a aquisição, organização, controle, propagação e uso dos dados para apoiar a tomada de decisões.

Não se pode olvidar que, sob o prisma da Nova Gestão Pública, observa-se a essencialidade do planejamento estratégico, uma vez que as decisões e ações devem ser orientadas para resultados, com foco nas demandas dos usuários/cidadãos (Leite, 2019). Nessa senda, pela análise dos problemas e falhas no sistema educacional ou administrativo da UFRN, pode-se criar políticas de ensino/gestão, reduzir erros, bem como estimular a participação acadêmica na geração de resultados. 
Urge destacar que a importância estratégica desta tecnologia extrapola as fronteiras da universidade. Com o sucesso da ferramenta na gestão acadêmica e administrativa, a UFRN ganhou competitividade e tornou-se referência, sobretudo para entidades correlatas. Diante disso, passou a licenciar e transferir o conhecimento e apoio técnico necessário para a implantação e uso do sistema em outras instituições mediante parcerias e contratos (UFRN, 2020b).

\section{CONSIDERAÇÕES FINAIS}

O presente artigo discorreu sobre o implemento dos Sistemas Integrados de Gestão desenvolvidos pela Universidade Federal do Rio Grande do Norte como instrumento de planejamento e execução das atividades de ensino, pesquisa e extensão desenvolvidas pela instituição. O objetivo era investigar se a inovação atendia aos princípios e características do modelo administrativo nominado como Nova Gestão Pública.

Consoante delineado ao longo do trabalho, a NGP baseia-se na introdução de mecanismos de mercado, adoção de ferramentas de gestão privada, promoção de competição entre fornecedores de bens e serviços públicos, redução de gastos, aumento da participação social, flexibilização do aparato estatal e elevação da qualidade, eficiência e transparência na prestação do serviço.

Embasada nessas diretrizes, a inovação constitui elemento fundamental para modernizar a máquina pública, bem como atender as demandas de uma sociedade diversificada e cada vez mais exigente. As respostas precisam ser rápidas. A atuação, transparente. Dados devem ser disponibilizados em plataformas de fácil acesso a fim de permitir o exercício do controle.

Diante desse contexto, verifica-se que o SIG-UFRN engloba diversas características da NGP: reduz custos e desperdícios; melhora o desempenho, eficiência e qualidade na prestação do serviço; concretiza a transparência e publicidade dos dados; permite o controle social; traz ferramentas de gestão participativa por avaliações continuadas e canais de comunicação como a ouvidoria.

Vale destacar que as diversas mudanças no modo de gerir a coisa pública trazem à baila a necessidade de uma utilização cada vez maior dos recursos tecnológicos para gestão da informação e conhecimento. Nessa linha, a publicidade e transparência alcançada pelos portais fomenta o acesso ao conhecimento produzido e simplifica o compartilhamento de informações entre os entes públicos e privados. Ademais, aumenta a interação entre administradores, usuários e sociedade.

Em suma, a iniciativa em fomento facilita a realização e controle das atividades institucionais. A otimização dos processos acarretou melhorias em três níveis: redução de tempo, redução de custos e melhoria da qualidade dos serviços. Resultado que se aproxima da premissa do discurso gerencialista, segundo a qual uma gestão eficiente permite alcançar resultados positivos mais rapidamente, satisfazendo o público alvo com menores custos.

Todavia, o uso integral das potencialidades do SIG-UFRN esbarra em algumas deficiências da instituição. Cumpre ressaltar a existência de informações errôneas no sistema, sobretudo quando a atualização dos dados depende dos gestores das unidades acadêmicas. Nessa senda, coordenações e departamentos de curso com localização errada ou sem especificação de sala em uma universidade com ampla extensão territorial fragiliza o atendimento ao público.

Outro problema relacionado ao ambiente organizacional reside na resistência de alguns servidores técnicos e docentes aderirem plenamente às mudanças. As razões podem ser diversas, tais como: dificuldade em operar sistemas informatizados, notadamente para servidores mais antigos; desconhecimento de alguma ferramenta; ausência de cursos específicos para algumas funcionalidades; falta de tempo ou estímulo para a qualificação.

Feitas tais considerações, resta patente o quanto os Sistemas Integrados de Gestão da UFRN contribuíram para a organização e compartilhamento de dados, melhoria do desempenho operacional e qualidade dos resultados obtidos. Contudo, resistências individuais à mudança organizacional e erros na disponibilização das informações podem comprometer o uso eficiente da ferramenta e, consequentemente, a qualidade do serviço público oferecido. 


\section{REFERÊNCIAS}

Bardin, L. (2010). Análise de conteúdo. (4. ed.). Lisboa: Edições70.

Brasil. (2004). Oficinas de planejamento estratégico: relatório consolidado. Brasília: CEGE.

Brasil. (1995). Plano Diretor da Reforma do Aparelho do Estado. Brasília: Imprensa Nacional.

Bresser-Pereira, L. C. (1998). Reforma do Estado para a cidadania: a reforma gerencial brasileira na perspectiva internacional. São Paulo: 34

Caiçara Jr, C. (2015). Sistemas Integrados de Gestão ERP: uma abordagem gerencial. (2. ed.). São Paulo: InterSaberes.

Ferlie, E., Asburner, L., \& Fitzgerald, L. (1999). A Nova Administração Pública em ação. Brasília: ENAP.

Ferreira, L. (2011). UFRN vende tecnologia da informação para todo o país. Disponível em http://www.tribunadonorte.com.br/noticia/ufrn-vende-tecnologia-da-informacao-para-todo-opais/169125

Gadelha, M. (2020). UFRN lidera número de conjuntos de dados abertos. Disponível em https://ufrn.br/imprensa/noticias/35696/ufrn-e-lider-em-numero-de-conjuntos-de-dados-abertos

Guerrero, O. (2019). Neoliberalismo y neogerencia pública. Revista Eletrônica de Administração, 25(2), 4-21.

Hood, C. (1991). A public management for all seasons? Public Administration, 69(1), 03-19.

Junquilho, G. S. (2010). Teorias da administração pública. Brasília: CAPES.

Kettl, D. F. (2000). The global public management revolution: a report on the transformation of governance. Washington, DC: Brookings Institution.

Lapuente, V., \& Walle, S. V. de. (2020). The effects of new public management on the quality of public services. Governance, 33(3), 461-475.

Leite, L. Q. (2019). História da reforma gerencial do Estado de 1995 (Tese de Doutorado, Fundação Getúlio Vargas). Disponível em https://bibliotecadigital.fgv.br/dspace/handle/10438/27464

Lourenço, N. V. (2016). Administração pública: modelos, conceitos, reformas e avanços para uma nova gestão. Curitiba: Intersaberes.

Matias-Pereira, J. (2016). Manual de gestão pública contemporânea. (5. ed.). São Paulo: Atlas.

Mesquita, A. de S., \& Ferreira, S. P. (1997). Fortalecer o serviço público e valorizar a cidadania: a opção australiana. Revista do Serviço Público, 48(3), 36-61.

Moreira, J. P. S., \& Lopes, C. A. (2016). Análise da implantação do Sistema de Gestão Integrada (SGI) em uma instituição de ensino superior. Anais do XXXVI Encontro Nacional de Engenharia de Produção, João Pessoa, 36. Disponível em http://www.abepro.org.br/biblioteca/TN_WIC_227_326_30187.pdf

Oliveira, E. R. (2019). Organizações sociais e o paradigma gerencial: as políticas públicas de saúde e as organizações sociais em Goiás. Goiânia: Kelps.

Paula, A. P. P. de. (2005). Por uma nova gestão pública: limites e potencialidades da experiência contemporânea. Rio de Janeiro: FGV.

Tomio, F. R. de L., \& Robl Filho, I. N. (2013). Accountability e independência judiciais: uma análise da competência do Conselho Nacional de Justiça (CNJ). Revista de Sociologia e Política, 21(45), 29-46. 
UFRN. (2020a). Página do Departamento de Ciências Sociais no Sistema Integrado de Gestão Atividades Acadêmicas. Disponível em https://sigaa.ufrn.br/sigaa/public/departamento/portal. jsf?id=136

UFRN. (2020b). Parceiros. Disponível em http://www.portalcooperacao.info.ufrn.br/pagina.php?a= parceiros\#

UFRN. (2020c). Sistemas Institucionais Integrados de Gestão - SIG. Disponível em https://docs.info. ufrn.br/doku.php

Vieira, J. N. (2018). Tecnologia da informação e comunicação (TIC) na gestão da Pós-Graduação Interdisciplinar da UFPA: um estudo de caso sobre o Sistema Integrado de Gestão de Atividades Acadêmicas (SIGAA). (Dissertação de Mestrado, Universidade Federal do Pará). Disponível em http://repositorio.ufpa.br/jspui/handle/2011/10345 